\title{
Impacts on construction costs of construction site environmental management
}

\author{
Siyuan Yin $^{1, a^{*}}$ \\ ${ }^{1}$ Chang an zhong road No.161, Xl' AN City, Shaanxi Province, China \\ ayinsiyuanhere@163.com,
}

Keywords: The environment of construction site; the management of environment; the cost of engineering; the impact on the cost.

Abstract. Nowadays, because of the environment factors, such as the related legal policy is imperfect and the management of the construction enterprise does not reach the designated purpose and the management of the construction enterprise does not reach the designated purpose, the environmental management of construction site has an important influence on the engineering cost. If we do not give an effective management to the environment of the construction site, it will give an adverse influence on engineering cost management and control. So the analysis to the influence which comes from the management of the engineering construction site on the engineering cost is necessary. This article analyzed influence of the management of the engineering construction site on the engineering cost from five aspects. These five aspects are the layout of the construction site, materials and equipment management of the construction site, the processing of construction waste on the construction site, the safety management of construction site, the natural environment management of the construction site, etc. This thesis expounds the influence which was given by the management of environment of the construction site on the engineering cost management and the importance.

\section{Background}

The construction site environment of project has the features: wild outdoor jobs, aloft jobs, high mobility, insecurity and so on. And the relevant laws and regulations of our country are not perfect, most of construction enterprises do a less than good job with the management of construction site environment. Therefore, the management of construction site environment has a noticeable influence on project costs. If the environmental management of construction site is not effective, it will have an adverse influence on management and control of project costs. So, it is necessary to analyze the influence on project costs which the environmental management of construction site creates.

\section{Overvie w of the environmental manage ment of construction site}

The environmental management of construction site this thesis explored includes: construction site plane layout; materials and equipment management; processing of construction waste; security and environment management; natural environment management.

The construction site plane layout is mainly used to: determine the placement of materials and equipment; reasonably divide construction operation area, secondary operation area, material stacking area and office- living area; reasonably plan roads, water and electricity lines. Ensure that the project can proceed orderly without interference, during the construction process. It ensures that required resources and service facilities can be combined effectively and proceed safely. Meanwhile reduce the secondary transportation of the materials as much as possible. The construction site plane layout plan is the basis of the site plane management, but also be important basis of the site dispatching and conducting.

The materials and equipment management refers to procurement, transportation, admission checking, placement and storage of the materials and equipment which is used during the construction process. It is also an important component of construction site environmental management. 
Construction waste refers to the sediment, spoil, abandoned materials, sludge and other waste which is generated when building, construction unit or individuals build, lay, demolish or repair all types of buildings, structures and pipe network, etc. These materials do not have any help for building itself. But they are produced in the construction process, in order to achieve the desired project building, they need to be handled accordingly. Because it is a whole process, it is more important to take account of segment management.

Security and environment management is an important part of construction site environmental management. The process, quality and cost of project are directly related to whether security and environment management is qualified.

Natural environment management is the key issue to be discussed in this thesis. Most construction phenomenon are in the open air environment, which makes the project be inevitably influenced by the natural environment. Here we do not discuss the influence of natural conditions (such as: rain, snow, wind, fog, haze and other weather conditions). We mainly discuss that due to poor construction site environmental management, the cost of project has an unnecessary increase.

\section{Impacts on construction costs of construction site environmental management}

Construction site plane layout. The overall plane layout of construction site should be compact and reasonable. Layout of temporary facilities should be convenient for worker productivity and living. Office buildings should be close to construction site. Minimize construction site area as much as possible, make full use of existing buildings or structures to reduce construction costs of construction facilities [1].

For the seating position of material, the improper seating position not only leads to contamination of material itself, but also leads to contamination of construction environment, increases intra-field secondary transportation distance, which inevitably leads to an increase of project costs. Related materials and equipment should be placed sequentially, without emergence of return route. Construction materials piled should be set in the range of vertical transportation machinery coverage, which can reduce the length of transport routes to reduce costs [2].

The layout of small-medium machinery and construction facilities should be in a safe environment and avoid the range of high-altitude objects falling. And employ prefabricated construction facilities to reduce relocation losses.

Transportation routes should be reasonably arranged to ensure the smooth flow of site transportation and to reduce the intra-field transportation costs. The layout of route should meet the transportation requirements of materials, components, etc. And every warehouse and stockyard can be reached through the routes. In order to reduce transportation costs, the closer the distance between load zone and other zones is the better. And it should meet the requirements of fire protection. So the route should be close to the place where is prone to fire, like buildings, timber yards, etc., which can ensure the vehicles can reach fire hydrant. And the width of fire street should not be less than the width laws and regulations specify to deal with the associated risks. The costs of dealing with risks should be decreased as much as possible. The construction site should make full use of existing roads or permanent road. According to the permanent road positive in the general building plan, first build roadbed as temporary road, after project ending, build pavement [3], which can greatly reduce the cost of road construction. The construction method of temporary road also has an influence on the management costs of construction site environment. If the temporary road grade is too high, the construction costs certainly will increase, but if the road can not meet the use requirements, it will lead to temporary road being faced with frequently repairing, which will make the repairing costs increase. Therefore, temporary road grade and construction methods can not be ignored.

Materials and equipment management. The materials and equipment management is an important component of construction site environmental management.

With the construction progress of the project, the site plane is arranged. The stage plane layout needs to be in accordance with the construction focus of the period. For decreasing the storage cost of materials, the materials admission time, admission number and storage position should be calculated and planned rigorously. If it is not handled properly, it will increase unnecessary costs [4], for 
example, if the cement has been produced more than three months, they are not put into use, so they need to be rechecked, which will increase the check costs.

The material costs are 60-70 percent of project costs, so in the project management, the result of material management directly affects the project costs. As construction unit, before building, they not only need research the source of required materials, collect providing material information and search the best material quality and price, but also calculate the actual amount of required material and equipment, and make the plan of material and equipment requirements, according to the construction organization design and related documents[5]. According to supplying situation of local material resource, make the construction material entry plan, in order to reduce the costs of material transportation and storage.

Processing of construction waste. It is estimated that 10 percent of the construction materials are wasted in the construction. Not only material purchasing and storage waste finance, but also processing of construction waste wastes finance.

Table 1. Impact on the cost of construction waste

\begin{tabular}{ccccccc}
\hline $\begin{array}{c}\text { Project } \\
\text { Name }\end{array}$ & $\begin{array}{c}\text { Building } \\
\text { area }\left(\mathrm{M}^{2}\right)\end{array}$ & $\begin{array}{c}\text { Project } \\
\text { Cost } \\
\text { (Million) }\end{array}$ & $\begin{array}{c}\text { The } \\
\text { amount of } \\
\text { waste }\left(\mathbf{M}^{3}\right)\end{array}$ & $\begin{array}{c}\text { Garbage } \\
\text { original value } \\
\text { (Million) }\end{array}$ & $\begin{array}{c}\text { Freight } \\
\text { (Million) }\end{array}$ & $\begin{array}{c}\text { Percent of project } \\
\text { cost accounting } \\
(\%)\end{array}$ \\
\hline Project A & 8100 & 640 & 1200 & 6 & 2.4 & 1.3 \\
Project B & 10800 & 1300 & 1100 & 5.5 & 2.2 & 0.6 \\
Project C & 11700 & 1265 & 1470 & 7.35 & 2.94 & 0.82 \\
Project D & 26700 & 2300 & 3150 & 15.78 & 6.3 & 0.96 \\
\hline
\end{tabular}

As is shown in Table 1, the proportion of resource waste and processing waste cost can not be ignored in the whole project [6]. Meanwhile construction waste cost also reflects the site management level of construction unit in the whole project. Therefore, by strengthening the level of technology and management, reduce the production of construction waste, improve the utilization efficiency of the material. Select the appropriate processing method and transport to reduce the costs of waste disposal and transportation.

Security and environment manage ment. In the construction site management, security and environment management is a vital part, it is not only related to the construction quality and progress of the project, is also related to the future of construction enterprises development. The complexity of the construction process and the defective quality of personnel will lead to security risks. Messy construction environment, confused management and poor security measures will lead to increase in the cost of security management. So the construction unit should strengthen the training of personnel technology and self-protection.

Natural environment management. The cost of construction site environment protection includes: the management cost for preventing environmental damage, the compensation charges for damaging environment, and the costs of environmental remediation and governance. The construction pollution refers to during the construction process, waste gas, dust, noise and waste solid pollute the environment, which is generated for transport, mechanical work, demolition and construction materials processing [7].

In the construction site, the construction technology of some enterprises is relatively backward, the construction process management is poor and construction workers lack environmental awareness, which cause serious ecological damage [8].

In today's environmental policy, the construction activities which cause the environmental destruction will be given appropriate fine. Also, the amount standard of fines increases gradually with the attention we pay to environmental protection increasing. In addition, the litigation cost the construction unit pays for environmental protection, time and effort litigation spends are much higher than the number of fines. Therefore, it is necessary for controlling project costs to strengthen protection and management of the natural environment in construction site and reduce the fines for poor construction site environmental management.

Again, the environmental destruction must be repaired and governed. And the affected residents must be given some compensation. For example, the contaminated river need to be cleaned up, 
contaminated water need to be resumed, the destroyed trees need to be re-planted. All these require a considerable investment of time, manpower, material and financial resources. The governance result has an impact on whether the government approves the construction unit working again [9].

To avoid the loss environmental pollution and destruction cause, the construction unit can execute a series of prevention measures before the environmental pollution and destruction, in order to reduce the environmental protection cost and keep the total costs in control. Such as: the construction site noise pollution prevention, air pollution prevention, water pollution prevention, solid waste pollution prevention and so on[10].

\section{Conclusions and Recommendations}

Effective construction site environmental management can not only greatly reduce the cost of the construction site environmental management, but can also help promote corporate environmental image and improve relations between the government and the local environmental protection departments thus ensure the smooth implementation of the project. Therefore, in the project implementation process, make a detailed cost-control plan for the construction site management. Construction site environmental management is an important part in the construction design, which should be paid the appropriate degree of attention to ensure the cost of processing the construction site environment is effectively controlled and reduced.

\section{References}

[1] Zhiyong Li, Yiyong Lang. Construction site layout methods and points [J]. Shanxi Architecture. 2011,37 (28): p100-101(In Chinese).

[2] Yong Feng. Building construction site layout [J]. Building materials in the world. 2011,32 (6): p98-100 (In Chinese).

[3] He Liang. The method of construction site layout machinery and transport roads [J]. Modern decoration theory. 2012, (05): p141-142(In Chinese).

[4] Tun Ren, Factors affecting construction project cost and method controlling construction project cost [J], Manager' Journal. 2014, 2 month (on stage): p345(In Chinese).

[5] Xiuzhi Guo. Discussion on the role of the construction project site management in the project cost[J]. Inner Mongolia Science Technology and Economy. 2009, (4): p87-91(In Chinese).

[6] Jiyi Xie, Shan cheng Zhao, Jinzeng Wu, Construction waste formation and its impact on project cost [J]. Henan Building Materials. 2002,2: p42-43(In Chinese).

[7] Chongguang Guan, The construction site and environmental protection[J]. Fujian environment. 1994,11 (1): p18-20(In Chinese).

[8] Yang Cheng, Zeliang Li, Guangmin Gu. Strategy of construction site protection and control [J]. Young Years. 2013,(2): p410-411(In Chinese).

[9] Kai Huang, Yi Chai. Site environmental management of cons truction enterprises [J]. Journal of Chongqing Architecture University. 2004,26 (3): p115-120(In Chinese).

[10] Chengyuan Lin, Xiujuan Li. Discussion on the construction site environmental risk management [J]. Heilongjiang Science and Technology Information. 2010,4: p192(In Chinese). 